\title{
KEANEKARAGAMAN DAN KARAKTERISTIK POHON BERSARANG ORANGUTAN (Pongo pygmaeus wurmbii) DI SUAKA MARGASATWA LAMANDAU KALIMANTAN TENGAH
}

\section{(Diversity and Characteristic Orangutan (Pongo pygmaeus wurmbii) Tree Nest At Lamandau Wildlife Reserve Central Kalimantan)}

\author{
Sosilawaty ${ }^{1)}$ Mohamad Rizal ${ }^{2)}$ Novera Fatmi Saragih ${ }^{3)}$ \\ Jurusan Kehutanan Fakultas Pertanian universitas Palangka Raya \\ Jl.Yos Sudarso Palangka Raya 73111 \\ Email : fapertaupr5@gmail.com
}

\begin{abstract}
The existence of orangutan (Pongo pygmaeus wurmbii) habitat is very important for orangutan life sustainbility. One of the borneo orangutan habitat is Lamandau Wildlife Reserve. Nest were one of the place that built for life sustainbility and used for breeding and place torestor sleep also place to play. The goal that this research were done is to know the variety, tree nest characteristic and orangutan nest characteristic with line transect method, after nest is found pathways were made along $1 \mathrm{~km}$ and wide $25 \mathrm{~m}$ for each right side and left side pathway. Nest observation were done three times transect repeat where the path between transect is $150 \mathrm{~m}$. Based of the observation result from Diversity Type Indices (H'), Richness Type Indices (R), and Eveness Type Indices (E) tree where orangutan nesting were at the high category. Tree characteristic where orangutan nesting dominated by kind of mahang (Macaranga hypoleuca), Puak (Artacarpus anisophyllus), bangan (Ervatamia macrocarpa), and ubar (Syzgium sp.). Nesting tree height and nest that dominated are at 10 to less than 25 meter from ground level. Tree diameter 10 to less than 40 centimeter. Orangutan nest characteristicat Lamandau Wildlife Reserve that dominating are nest withclass C,D, and E. Nest position that more dominating are nest position 1.
\end{abstract}

Keywords: nesttree, diversity, characteristic, orangutan.

\begin{abstract}
Abstrak
Keberadaan habitat orangutan(Pongo pygmaeus wurmbii) sangat penting untuk kelangsungan hidup orangutan. Salah satu habitat orangutan Kalimantan yaitu Suaka Margasatwa (SM) Lamandau. Sarang merupakan salah satu yang dibangun untuk kelangsungan hidup dan digunakan untuk tempat berkembang biak dan tempat istirahat atau tidur juga tempat bermain. Tujuan dilakukannya penelitian ini adalah untuk mengetahui keanekaragaman, karakteristik pohon tempat bersarang dan karakteristik sarang orangutandengan metode linetransect, setelah sarang ditemukan dibuat jalur sepanjang $1 \mathrm{~km}$ dan lebar $25 \mathrm{~m}$ pada masing-masing sisi kanan dan kiri jalur. Pengamatan sarang dilakukan dengan tiga kali ulangan transek dimana jarak antar transek adalah $\pm 150 \mathrm{~m}$. Berdasarkan hasil pengamatan Indeks Keanekaragaman jenis (H'), Indeks Kekayaan Jenis (R), dan Indeks Kemerataan Jenis (E) pohon tempat bersarang orangutan masuk ke dalam kategori tinggi. Karakteristik pohon tempat bersarang orangutan didominasi oleh jenis pohon mahang (Macarangahypoleuca), puak (Artacarpusanisophyllus), bangan (Ervatamiamacrocarpa), dan ubar (Syzygiumsp.). Tinggi pohon sarang dan tinggi sarang yang mendominasi adalah ketinggian 10 sampai kurang dari 25 meter dari permukaan tanah. Diameter pohon sarang yang mendominasi adalah diameter 10 sampai kurang dari 40 centimeter. Karakteristik sarang orangutan pada SM Lamandau yang mendominasi adalah sarang dengan kelas C,D, dan E. Posisi sarang yang paling dominan adalah posisi sarang 1 .

Kata kunci: pohon sarang, keanekaragaman, karakteristik, orangutan.
\end{abstract}




\section{PENDAHULUAN}

Suaka Margasatwa Lamandau awalnya adalah kawasan Hutan Produksi Tetap dan Hutan Produksi yang dikonversi pada sebagian kelompok hutan. Suaka Margasatwa Lamandau memiliki luas \pm 76.110 ha berdasarkan penunjukan Surat Keputusan Menteri Kehutanan Nomor:162/Kpts-II/1998 tanggal 26 Februari 1998. Saat ini, Suaka Magasatwa Lamandau merupakanlokasi penting karena merupakan salah satu kawasan konservasi yang digunakansebagai lokasi pelepasliaran orangutan Kalimantan hasil rehabilitasi.

Orangutan (Pongo pygmaeus wurmbii) adalah spesies langka dan sepenuhnya dilindungi oleh perundang-undangan Indonesia yang keberadaannya semakin terancam punah, orangutan (Pongo pygmaeus wurmbii) diklasifikasikan oleh CITES (Convention on International Trade in Endangered of Wild Species of Fauna and Flora) ke dalam kategori Appendix I (spesies yang dilarang untuk perdagangan komersial internasional karena sangat rentan terhadap kepunahan) sedangkan IUCN (International Union for Conservation of Nature and Natural Resources) ke dalam kategori Endangered/genting. Beberapa ancaman utama yang dihadapi oleh orangutan (Pongo pygmaeus) adalah kehilangan habitat,pembalakan liar, kebakaran hutan, perburuan dan perdagangan (Departemen Kehutanan, 2007). Sebagian hidup Orangutan dihabiskan di atas pohon, baik itu dalam hal mencari makan maupun beristirahat. Orangutan membutuhkan tempat tinggal, tempat berlindung maupun bermain dan berkembang biak untuk kelangsungan hidupnya. Habitat sangat mempengaruhi kehidupan orangutan. Hutan merupakan habitat yang menyediakan vegetasi yang mampu digunakan orangutan sebagai sumber pakan (buah) dan tempat membuat sarang untuk beristirahat. Kegiatan pembuatan sarang membantu pembukaan kanopi sehingga sinar matahari dapat masuk hingga lantai hutan.

Sarang dibangun untuk kelangsungan hidup dan digunakan untuk tempat berkembang biak dan tempat istirahat, dan sarang orangutan dapat ditentukan dengan teknik konservasi yang tepat untuk tidur juga tempat bermain. Setiap individu memiliki letak sarang yang berbeda sesuai dengan kebutuhan dan lingkungannya pada saat bersarang. Sarang bagi orangutan merupakan salah satu bukti yang paling penting untuk melihat keberadaannya di suatu kawasan. Fungsi sarang adalah tempat untuk bermain bagi orangutan muda, tempat berlindung, melahirkan, dan aktivitas makan. Informasi tentang karakteristik dan keanekaragaman pohon bersarang diterapkan di lapangan.

Penelitian ini di gunakan sebagai acuan dalam rangka pengembangan, pengelolaan, perlindungan dan pelestarian, dengan meneliti keanekaragaman dan karakteristik pohon tempat bersarang Orangutan (Pongo pygmaeus wurmbii) serta karakteristik sarang Orangutan (Pongo pygmaeus wurmbii) dikawasan Suaka Margasatwa di Kabupaten Sukamara dan Kabupaten Kotawaringin Barat Kalimantan Tengah.

\section{METODOLOGI PENELITIAN}

Penelitian dilaksanakan di Kawasan Suaka Margasatwa Lamandau Kabupaten Sukamara dan Kabupaten Kotawaringin Barat Kalimantan Tengahpada bulan Maret -Agustus 2019. Alat yang di gunakan : Pita diameter, meteran roll, tali rafiah, GPS, Kamera, alat tulis menulis, tally sheet, komputer.Pembuatan Jalur dibuat pada 3 titik pengamatan sebagai sampel yang dapat mewakili areal Suaka Margasatwa Lamandau, yaitu di Camp Rasak, di Camp Gemini dan Camp Buluh. Pembuatan jalur dimulai dengan melihat keberadaan sarang dan pengambilan data dengan metode line transect secara purposive sampling. Setelah sarang ditemukan dibuat jalur sepanjang 1 
$\mathrm{km}$ dan lebar $25 \mathrm{~m}$ pada masing-masing sisi kanan dan kiri jalur. Pengamatan sarang dilakukan dengan tiga kali ulangan transek dimana jarak antar transek adalah $\pm 150 \mathrm{~m}$

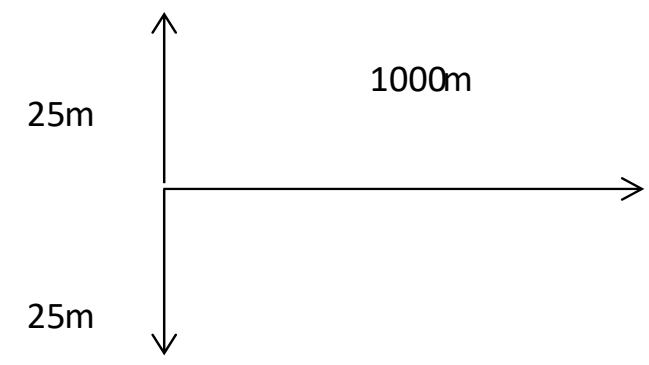

Gambar 1. Jalur line transect

\section{Analisis data pengamatan pohon Sarang.}

Pengambilan data vegetasi hanya pada tingkat pohon dengan menggunakan metode line transect pada gambar 3.1. Data pengamatan pohon sarang yang diambil adalah: Jenis pohon tempat bersarang, tinggi pohon tempat bersarang dari permukaan tanah, diameter pohon tempat bersarang.

\section{Pengamatan Sarang}

\section{a. Tinggi sarang pada pohon}

\section{b. Kelas sarang orangutan :}

1.Sarang kelas A adalah sarang yang masih baru dan dicirikan dengan warna daun

yang masih hijau.

2.Sarang kelas B atau sarang yang relatif baru merupakan campuran dari

daun-daun yang berwarna hijau dengan daun-daun kering

3.Sarang kelas C yaitu berwarna coklat, tetapi bentuk sarang masih utuh .

4.Sarang kelas D adalah tipe sarang yang sangat tua yang dicirikan dengan adanya

lubang pada sarang.

5.Sarang kelas E atau hampir hilang yaitu kelas sarang yang dicirikan dengan

tidak ada daun, sedikit ranting dan bentuk sarang hampir hilang.

c. Posisi sarang, menurut Prasetyo dalam Putra (2012) :

1.Posisi 0, merupakan posisi sarang yang sejajar dengan tanah.
2.Posisi 1, sarang berada dipangkal cabang utama pohon.

3.Posisi 2, sarang terletak di bagian tengah cabang atau di ujung percabangan

4.Posisi 3, sarang berada di pucuk pohon.

5.Posisi 4, sarang terletak diantara dua percabangan dari dua atau lebih individu pohon yang berbeda.

\section{Indeks Keanekaragaman Jenis}

Analisis data indeks keanekaragaman jenis pohon tempat bersarang orangutan dihitung dengan menggunakan rumus menurut Shannon (1949) dalam Indriyanto (2006) sebagai berikut:

$\mathrm{H}^{\prime}=-\Sigma \frac{n i}{N} \ln \frac{n i}{N}$

Keterangan :

$\mathrm{H}^{\prime} \quad$ : Indeks keanekaragaman jenis

ni : Jumlah individu suatu jenis

$\mathrm{N}$ : Jumlah individu seluruh jenis

ln : Logaritma natural

Berdasarkan derajat keanekaragaman jenis dapat didefenisikan dengan kriteria Brower dan Zar (1997) dalam Septiadi (2012) sebagai berikut: $H^{\prime}<1=$ menunjukan tingkat keanekaragaman jenis yang rendah

$1 \leq \mathrm{H}^{\prime} \leq 3=$ menunjukan tingkat keanekaragaman jenis yang sedang

$\mathrm{H}^{\prime}>3$ = menunjukan tingkat keanekaragaman jenis yang tinggi

\section{Indeks Kekayaan Jenis}

Indeks kekayaan jenis, menggunakan rumus indeks Margalef dalam Ludwig dan Reynolds (1988) adalah sebagai berikut:

$\mathrm{R}=\frac{s-1}{\ln N}$

Keterangan :

$\mathrm{R}$ : indeks kekayaan jenis (indices of species richness)

S : jumlah total jenis dalam suatu habitat (species per habitat)

$\mathrm{N}$ : jumlah individu pada suatu habitat (individu per habitat)

$\ln$ : logaritma natural 
Maguran (1988) dalam Trison (2014) menyatakan bahwa kriteria yang digunakan untuk menginterpretasikan kekayaan jenis yaitu:

$\mathrm{R}<3,5=$ kekayaan jenis rendah

$3,5 \leq \mathrm{R} \leq 5=$ kekayaan jenis sedang $\mathrm{R}>5=$ kekayaan jenis tinggi

\section{Indeks Kemerataan Jenis}

Menentukan proporsi kelimpahan jenis digunakan indeks kemerataan dengan menggunakan rumus Pielou dalam Odum (1971) adalah sebagai berikut:

$$
\mathrm{E}=\frac{\mathrm{H} \prime}{\ln S}
$$

Keterangan :

E : Indeks kemerataan

H' : Indeks keanekaragaman Shannon

$\mathrm{S} \quad$ : Jumlah jenis

ln : logaritma natural

Magurran (1988) dalam Trison (2014), menyatakan kriteria kemeratan jenis sebagai berikut:

HASIL DAN PEMBAHASAN

\section{Jenis Pohon Sarang Orangutan (Pongo} pygmaeus wurmbii) Jenis pohon sarang
$\mathrm{E}<0,3=$ menunjukkan kemerataan jenis tergolong rendah

$0,3 \leq \mathrm{E} \leq 0,6=$ kemerataan jenis tergolong sedang

E $>0,6=$ kemerataan jenis tergolong tinggi

Tabel 1.1 Jenis Pohon Sarang Orangutan

\begin{tabular}{llll}
\hline \multicolumn{1}{c}{ Nama Pohon } & \multicolumn{1}{c}{ Namailmiah } & \multicolumn{1}{c}{ Famili } & Jumlah \\
\hline Mahang & Macaranga hypoleuca & Euphorbiaceae & 17 \\
Puak & Artacarpus anisophyllus & Moraceae & 13 \\
Ubar & Syzygium sp. & Myrtaceae & 10 \\
Bangan & Ervatamia macrocarpa & Apocynaceae & 8 \\
Bakunyit & Diospyros polita & Ebenaceae & 7 \\
Lanan & Shorea leprosula Miq & Dipterocarpaceae & 7 \\
Bayuan & Crudia gracilis Prain & Leguminosae & 4 \\
Mendoking & Elaeocarpus griffithii & Elaeicarpaceae & 4 \\
Bentan & Parastemon urophyillus & Leguminosae & 3 \\
Gerunggang & Cratoxylum arborescens & Hypericaceaea & 3 \\
Kariwaya & Ficus binnendijkii & Moraceae & 3 \\
Marigalang & Alstonia angustifolia Wall & Apocynaceae & 3 \\
Papung & Sandoricum emarginatum & Meliaceae & 3
\end{tabular}


Volume 2 Nomor 1 Juli 2020:1-10

\begin{tabular}{llll} 
Barbasung & Polyalthia lateriflora & Annonaceae & 2 \\
Kengkoban & Neoscortechinia philippinensis & Euphorbiaceae & 2 \\
Lamanaduk & Diospyros pilosanthera & Ebenaceae & 2 \\
Nyarang bukit & Goniothalamus tapis & Annonaceae & 2 \\
Rasak & Vatica rasak & Dipterocarpaceae & 2 \\
Rengas & Gluta renghas & Anacardiaceae & 2 \\
Satar & Bouea oppositifolia & Anacardiaceae & 2 \\
Badaru & Stemonurus secundiflorus & Stemonuraceae & 1 \\
Gandis & Garcinia parfivolia & Clusiaceae & 1 \\
Idat & Cratoxylum glaucum & Hypericaceaea & 1 \\
Makai & Mezzettia parviflora & Annonaceae & 1 \\
Mantangur & Callophyllum sp & Clusiaceae & 1 \\
Medang & Actinodaphne sp & Lauraceae & 1 \\
Munsap & Calophyllum lanigerum & Clusiaceae & 1 \\
Nanasi & Syzygium zeylanicun & Myrtaceae & 1 \\
Pampasir & - & - & 1 \\
Pansulan & Pternandra caerulescens & Melastomataceae & 1 \\
Pantis & Callophyllum pulcherrimum & Clusiaceae & 1 \\
Pompaning & Quercus bennettii & Fagaceae & 1 \\
Trantang & Campnospermasp & Anacardiaceae & 1 \\
Total & & & 112 \\
\hline \hline
\end{tabular}

Hasil pengamatan pohon tempat bersarang orangutan (Pongo pygmaeus wurmbii) di menunjukkan pohon yang paling banyak ditemukan sarang adalah pohon mahang (Macaranga hypoleuca), puak (Artacarpus anisophyllus), ubar (Syzygium sp.) danbangan (Ervatamia macrocarpa). Pohon mahang yang paling disukai orangutan dalam membuat sarang karena pohon mahang memiliki daun yang lebar sehingga sangat cocok digunakan orangutan untuk berlindung. Pohon-pohon yang paling banyak ditemukan sarang merupakan pohon pakan. Hal ini terjadi karena pohon pakan yang digunakan sebagai tempat bersarang merupakan cara orangutan untuk menghemat energi. Orangutan dalam pemilihan jenis pohon sarang biasanya lebih memilih pohon yang berada di dekat pohon yang sedang berbuah.Pohon pakan yang sedang tidak berbuah biasanya dijadikan sarang oleh orangutan dan orangutan juga biasanya membuat sarang pada pohon lain yang ada didekat pohon pakan yang sedang berbuah karena menghindari persaingan atau kontak langsung dengan satwa lainnya yang juga memakan buah pakan tersebut

Ketersediaan pohon sarang dan pakan yang cukup tinggi pada lokasi penelitian dapat dilihat dari banyaknya jenis pohon yang ditemukan khususnya pohon pakan. Hal ini menunjukkan bahwa penelitian masih terjaganya habitat orangutan pada lokasi penelitian. Menurut Muin (2007) tingkat kesesuaian habitat orangutan dinilai berdasarkan pada duakomponen biotik utama yakni ketersediaan pohon sarang dan pohon pakan dihabitatnya. Hal ini karena kedua komponen tersebut merupakan unsur pentinguntuk menjamin kelangsungan hidup orangutan di suatu habitat. Menurut Prayogo (2014) bahwa habitat yang memiliki kesesuaian tinggi bagi orangutan merupakan daerah yang memiliki tutupan lahan yang baik dan umumnya banyak dijumpai pohon sebagai sumber pakan orangutan. 


\section{Tinggi Pohon Sarang dan Sarang Orangutan (Pongo pygmaeus wurmbii)}

Hasil pengamatan pohon tempat bersarang orangutan ditemukan sarang dengan tinggi yang berbeda. Tinggi pohon yang paling disukai untuk membuat sarang adalah 16-20 $\mathrm{m}$ dengan persentase tertinggi $29 \%$ diikuti dengan tinggi pohon 11-15 m dengan persentase terendah $27 \%$, tinggi pohon 5-10 m dengan persentase $19 \%$, tinggi pohon 21-25 $\mathrm{m}$ dengan persentase $13 \%$, tinggi pohon $26-30 \mathrm{~m}$ dengan persentase $7 \%$, tinggi pohon $31-35 \mathrm{~m}$ dengan persentase $4 \%$, dan tinggi pohon $36-40 \mathrm{~m}$ dengan persentse terendah $1 \%$.

Tinggi sarang orangutan yang paling disukai adalah tinggi sarang 11-15 $\mathrm{m}$ dengan persentase $29 \%$ diikuti dengan tinggi sarang $5-10 \mathrm{~m}$ dengan persentase $26 \%$, tinggi sarang $16-20 \mathrm{~m}$ dengan persentase $25 \%$, tinggi sarang $21-25 \mathrm{~m}$ dengan persentase $11 \%$, tinggi sarang 26-30 $\mathrm{m}$ dengan persentase $7 \%$, tinggi sarang 31-35 m dengan persentase terendah $2 \%$. Pemilihan tinggi pohon sarang dan sarang di lokasi penelitian yang paling disukai orangutan tergantung kebutuhan orangutan dan keamanan yang didapat. Orangutan juga membuat sarang tergantung dengan struktur hutan tempat orangutan itu berada. Biasanya orangutan akan membuat sarang rendah untuk sarang istirahat siang dan membuat sarang tinggi untuk istirahat malam agar terhindar dari predator yang mengganggu.

Pemilihan tinggi pohon sarang dan tinggi sarang orangutan yang ditemukan pada ketinggian yang rendah 5-10 m terjadi karena pada lokasi peneltian orangutan betina yang memiliki anak yangbaru belajar membuat sarang dan biasanya membuat sarang rendah digunakan sebagai sarang istirahat siang. Orangutan dalam memilih tinggi pohon sarang dan sarang di lokasi penelitian yang semakin tinggi semakin kurang diminati orangutan. Menurut Pujiyani (2009) Pohon yang tingginya lebih dari 25 meter, kurang disukai orangutan untuk membuat sarang karena kondisinya yang tidak terlindungi dari terpaan angin. Apabila sarang berada pada ketinggian tersebut maka diperkirakan akan menyulitkan orangutan untuk mengawasi kondisi di sekitarnya, karena dari pohon yang lebih tinggi akan sulit melihat kondisi di bawah yang tertutup tajuk pepohonan yang lebih rendah.

\section{Diameter Pohon Sarang Orangutan (Pongo pygmaeus wurmbii)}

Hasil pengamatan diameter pohon tempat bersarang ditemukan sarang dengan diameter yang berbeda. Diameter pohon yang paling disukai orangutan untuk membuat sarang adalah 0-20 cm dengan persentase tertinggi $45 \%$ diikuti dengan diameter $21-30 \mathrm{~cm}$ dengan persentase $30 \%$, diikuti dengan diameter $31-40 \mathrm{~cm}$ dengan persentase $16 \%$, diameter $41-50 \mathrm{~cm}$ dengan persentase $6 \%$, diameter $51-60 \mathrm{~cm}$, diameter $71-80 \mathrm{~cm}$, diameter $81-90 \mathrm{~cm}$ dengan persentase persentase terendah $1 \%$. Diameter pohon bersarang orangutan paling banyak ditemukan ialah yang berukuran relatif kecil dengan diameter 0-20 cm, sedangkan untuk pohon bersarang berdiameter besar sangat sedikit ditemukan. Hal ini terjadi karena habitat hutan yang ada dilokasi penelitian merupakan hutan sekunder bekas hutan produksi.

Orangutan dalam memilih pohon sebagai sarang cenderung pohon berdiameter relatif kecil $(0-20 \mathrm{~cm})$ dengan persentase 44,65\%, namun menurut penelitian Muin (2007) diameter pohon mempunyai pengaruh yang kecil bagi Orangutan Kalimantan dalam pemilihan pohon sarang, peran faktor diameter lebihbersifat dukungan kepada faktor jumlah jenis pakan dalam mempengaruhikeberadaan sarang pada pohon tertentu. Relatif kecilnya diameter pohon sarang pada lokasi penelitian sangat berpengaruh terhadap posisi sarang orangutan yang lebih menyukai membuat sarang pada posisi 1 yaitu sarang yang berada pada pangkal cabang. Posisi ini sangat cocok untuk pohon sarang yang berdiameter kecil karena sangat kuat dan 


\section{Jurnal Penelitian Kehutanan Bonita}

Volume 2 Nomor 1 Juli 2020:1-10

dapat menopang tubuh orangutan. Diameter pohon sarang sangat berkaitan erat dengan posisi sarang orangutan.

\section{Kelas Sarang Orangutan (Pongo pygmaeus} wurmbii)
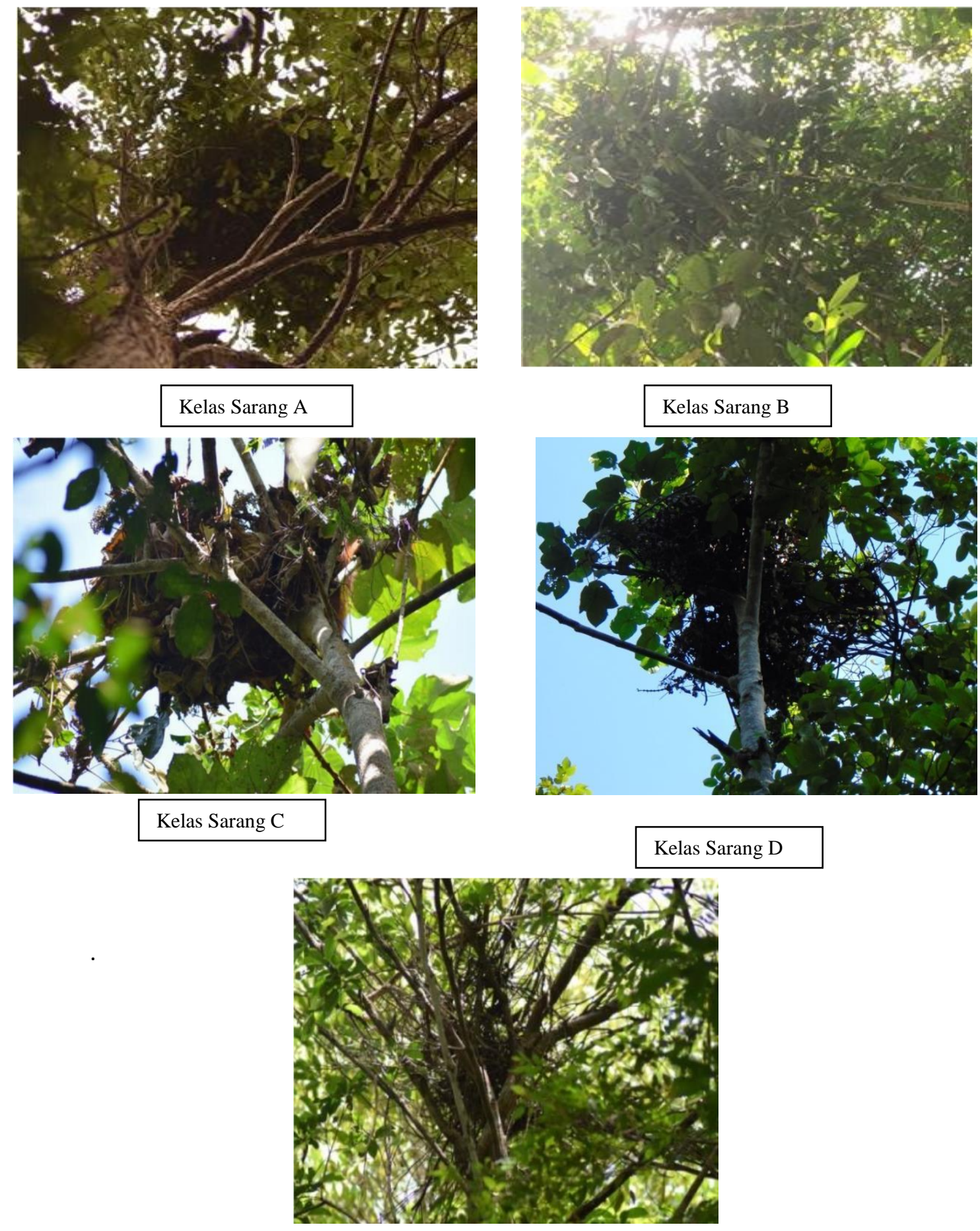

Kelas Sarang E 
Hasil pengamatan kelas sarang orangutan ditemukan 5 (lima) kelas sarang yang berbeda. Kelas sarang yang paling banyak ditemukan adalah kelas sarang tipe C,D, dan E. Kelas sarang tipe $\mathrm{C}$ adalah sarang yang belum terlalu lama ditinggalkan namun daun penyusunnya sudah mengering dan bentuk sarang masih utuh, kelas sarang D ditandai dengan warna daun pada sarang yang dipergunakan telah berubah menjadi coklat hingga kehitaman, dan kelas sarang E yaitu kelas sarang yang dicirikan dengan tidak ada daun, sedikit ranting dan bentuk sarang hampir hilang, dan pada saat melakukan pengamatan juga dijumpai orangutan yang sedang berada di dalam sarang. Kehadiran orangutan di suatu kawasan dipengaruhi oleh pohon pakan yang sedang berbuah. Dimana saat terdapat pohon pakan yang sedang berbuah, orangutan membuat sarang didekat pohon pakan tersebut.

Tipe sarang kelas A ditandai dengan sarang yang masih baru dan dicirikan dengan warna daun yang masih hijau dan sarang kelas B ditandai dengan sarang yang relatif baru merupakan campuran dari daun-daun yang berwarna hijau dengan daun-daun kering. Kedua tipe sarang ini sangat sulit ditemukan khususnya kelas sarang A. Hal ini terjadi karena orangutan biasanya cenderung lebih menyukai memperbaiki sarang yang ada daripada membuat sarang baru. Menurut Nawangsari (2016) berdasarkan pengamatan terdahulu, di lapangan jarang ditemukan sarang kelas A (sarang baru dengan daunnya segar berwarna hijau).

Penelitian terdahulu di Taman Nasional Tanjung Puting Kalimantan Tengah yaitu banyak menemukan bentuk sarang sudah bolong-bolong dan tidak utuh lagi (kelas C), sehingga kelas $\mathrm{C}$ merupakan kelas ketahanan dengan persentase terbesar yang ditemukan selama penelitian berlangsung, dengan banyaknya kelas $\mathrm{C}$ ditemukan pada lokasi pengamatan menandakan bahwa periode sebelum melakukan penelitian tingkat kehadiran orangutan sangat tinggi, orangutan kerap menggunakan habitat ini dalam memenuhi kebutuhan sehari-hari (Rahman. 2010).

Orangutan dalam membuat sarang tidur biasanya tidak jauh dari pohon pakan terakhir yang dikunjunginya pada hari itu. Hal ini berhubungan dengan kemudahan untuk akses sumber pakan pada keesokan harinya (MacKinnon. 1972 dalam Fauzan, 2010). Kelas sarang bergantung pada jenis pohon, temperatur, dan kelembaban udara, termasuk sarang yang dibuat untuk istirahat di siang hari atau untuk bermalam (Bismark, 2005).

\section{Posisi Sarang Orangutan (Pongo pygmaeus wurmbii)}

Hasil pengamatan posisi sarang orangutan ditemukan 5 (lima) posisi sarang yang berbeda. Posisi sarang yang paling banyak ditemukan adalah posisi 1 . Posisi 1 merupakan posisi yang paling aman bagi orangutan untuk membuat sarang karena posisi ini dianggap mampu menopang bobot badan orangutan khususnya pada orangutan dewasa. Posisi sarang 1 berada di pangkal cabang utama pohon. Penelitian terdahulu menunjukkan bahwa sarang orangutan yang ditemukan cenderung berada pada posisi satu (pangkal percabangan pohon utama) dan dua (ujung percabangan pohon). Hal ini karena posisi tersebut nyaman untuk istirahat. Selain itu, juga menyebabkan sarang tidak mudah rusak dan kuat untuk menahan berat tubuh orangutan (Nawangsari, 2016).

\section{Indeks Keanekaragaman Jenis (H').}

Pengukuran keanekaragaman jenis dapat dilakukan dengan mengukur langsung pada obyek/organisme yang terkait. Aspekaspek yang dapat diamati dalam rangka pengukuran keanekargaman jenis meliputi: kerapatan, frekuensi, dan dominansi (Istomo, 1995).

Indeks Keanekaragaman Jenis $\left(\mathrm{H}^{\prime}\right)$ pohon tempat bersarang orangutan adalah 2,99 dengan kategori sedang. Menurut Haryanto (1995), bahwa tinggi rendahnya 
keanekaragaman jenis tergantung dari jenis yang menyusunnya yang ditunjukan oleh kelimpahan individu jenis dan dominan atau tidaknya suatu jenis. Santosa (1995) dalam Trison (2014) keanekaragaman jenis merupakan istilah untuk menunjukkan derajat keanekaragaman sumber daya hayati (dalam hal ini spesies) pada suatu wilayah.

Besarnya nilai Indeks Keanekaragaman Jenis ( $\left.H^{\prime}\right)$ untuk pohon tempat bersarang orangutan juga menunjukkan hutan sebagai tempat vegetasi (pohon bersarang/pohon pakan) dan satwa (orangutan) yang masih terjaga.

\section{Indeks Kekayaan Jenis (R)}

Indeks Kekayaan Jenis (R) pohon tempat bersarang orangutan adalah 6,78 dengan kategori tinggi. Nilai Indeks Keanekaragaman Jenis (R) merupakan indeks yang digunakan untuk menggambarkan kekayaan jenis dalam suatu komunitas. Nilai Indeks Keanekaragaman Jenis (R) meningkat dengan makin meningkatnya jumlah individu jenis dalam komunitas.

Kekayaan Jenis (R) pohon tempat bersarang orangutan yang terdapat pada kawasan dapat dipengaruhi oleh jumlah jenis dan banyaknya individu untuk semua jenis. Nilai Indeks Kekayaan Jenis (R) pohon tempat bersarang orangutan juga menunjukkan kekayaan jenis pohon sarang pada suatu kawasan. Kategori tinggi pada hasil penelitian Nilai Indeks Kekayaan Jenis (R) menunjukkan bahwa kekayaan jenis pohon tempat bersarang di kawasan penelitian juga tinggi.

\section{Indeks Kemerataan Jenis (E)}

Indeks Kemerataan Jenis (E) pohon tempat bersarang orangutan adalah 0,63 dengan kategori tinggi. Indeks Kemerataan yang tinggi menunjukkan bahwa pohonpohon tempat bersarang orangutan tersebar merata pada jenis-jenis yang ditemukan. Menurut Bratawinata (2001) yaitu ukuran kemerataan dapat digunakan sebagai indikator adanya gejala antara jenis dalam suatu komunitas yang hadir secara lebih merata pada suatu tingkat pertumbuhan vegetasi. Hal ini juga sesuai dengan pendapat Santoso (1995) dalam Nunung (2007) bahwa indeks kemerataan menunjukkan ukuran kemerataan proporsi jumlah individu pada setiap spesies yang dijumpai suatu komunitas tertentu. Nilai suatu indeks kemerataan dapat dikatakan tinggi apabila jumkah total individu dapat terbagi rata pada setiap jenis yang ada.

\section{KESIMPULAN}

Indeks Keanekaragaman jenis (H') pohon tempat bersarang orangutan (Pongo pygmaeus wurmbii) masuk ke dalam kategori sedang. Indeks Kekayaan Jenis (R) pohon tempat bersarang orangutan termasuk ke dalam kategori tinggi, dan indeks Kemerataan Jenis (E) pohon tempat bersarang orangutan masuk ke dalam kategori tinggi. Karakteristik pohon tempat bersarang orangutan (Pongo pygmaeuswurmbii) pada SM Lamandau didominasi oleh jenis pohon mahang (Macaranga hypoleuca), puak (Artacarpus anisophyllus), bangan (Ervatamia macrocarpa), dan ubar (Syzygium sp.). Tinggi pohon sarang dan tinggi sarang yang mendominasi adalah Ketinggian 10 sampai kurang dari 25 meter dari permukaan tanah. Diameter pohon sarang yang mendominasi adalah diameter 10 sampai kurang dari 40 centimeter. Karakteristik sarang orangutan (Pongo pygmaeus wurmbii) yang mendominasi adalah sarang dengan kelas C,D, dan $\mathrm{E}$, dan posisi sarang yang paling dominan adalah posisi sarang 1 .

\section{DAFTAR PUSTAKA}

Bismark, M. 2005. Estimasi Populasi Orang Utan dan Model Perlindungannya di Kompleks Hutan Muara Lesan Berau, Kalimantan Timur. Pusat Penelitian dan Pengembangan Hutan dan Konservasi Alam, Bogor.

Departemen Kehutanan. 2007. Strategi dan Rencana Konservasi Orangutan Indonesia 2007-2017. Direktorat Jenderal Perlindungan Hutan dan 
Konservasi Alam. Departemen Republik Indonesia. Jakarta.

Fauzan, P. M. 2010. Pendugaan Umur Sarang Orangutan Sumatera Reintroduksi (Pongo abelii Lesson 1872) Berdasarkan Perubahan Ukuran Dan Warna Di Ekosistem Taman Nasional Bukit Tigapuluh. IPB. Bogor .

Indriyanto. 2006. Ekologi Hutan. PT. Bumi Aksara. Jakarta

Istomo. 1995. Teknik Pengukuran dan Pemantauan Keanekaragaman Hayati Tumbuhan Alam. Fakultas Kehutanan IPB. Bogor.

Ludwig,J.A, and J.F.Reynold.1988. Statistical Ecology. Jhon Willey \& Son.Toronto.

Muin A. 2007. Analisis tipologi pohon tempat bersarang dan karakteristik sarang orangutan (Pongo pygmaeus wurmbii Groves, 2001) di Taman Nasional Tanjung Putting Kalimantan. Bogor (ID): Institut Pertanian Bogor.

Nawangsari, Ventie Angelia. 2016. Tingkat Keberhasilan Orangutan (Pongo Pygmaeus Wurmbii Groves,2001) ExCaptive Pasca Pelepasliaran Dan KesesuaianHabitatnya Di Suaka Margasatwa Lamandau. Sekolah Pascasarjana Institut Pertanian Bogor. Bogor.

Nunung, Supariah. 2007. Keanekaragaman Jenis Primata Di Kawasan Hutan Rawa Gambut Eks PLG Blok C Kalampangan Kecamatan Sebangau Kota Palangka Raya. Fakultas Pertanian UPR. Palangka Raya.

Odum.E.P. 1971.Fundamental of Ecology.Third Editions, W.B.Sounders Company,Tokyo, Japan.

Prayogo H. 2014. Pendugaan kesesuaian habitat orangutan Kalimantan (Pongopygmaeus pygmaeus) dan karakteristik genetiknya di Kabupaten Kapuas Hulu Kalimantan
Barat [tesis]. Bogor (ID): Institut Pertanian Bogor.

Pujiyani, H. 2009. Karakteristik Pohon Tempat Bersarang Orangutan Sumatera (Pongo abelii Lesson, 1827) di Kawasan Hutan Batang Toru, Kabupaten Tapanuli Utara, Sumatera Utara. Skripsi. Departemen Konservasi Sumberdaya Hutan dan Ekowisata. Fakultas Kehutanan. Institut Pertanian Bogor. Bogor.

Putra, A. P. 2012. Proses Kemandirian Orangutan (Pongo pygmaeus wurmbii) Betina di stasiun Penelitian Tuanan Kalimantan Tengah. Universitas Indonesia. Depok.

Rahman D.A. 2010. Karakteristik habitat dan preferensi pohon sarang orangutan(Pongo pygmaeus wurmbii) di Taman Nasional Tanjung Puting (Studi kasus Camp Leakey). Jurnal Primatologi Indonesia 7(2): 37-50.

Septiadi, M. 2012. Keanekaragaman Jenis Satwa Liar di Areal Arboretum Nyaru Menteng Palangka Raya Kalimantan Tengah. Fakultas Pertanian UPR. Palangka Raya.

Trison, K. 2014. Keanekaragaman Fauna di Kawasan Perlindungan Plasma Nutfah IUPHHK- HA PT.AUSTRAL BINA. Fakultas Pertanian UPR. Palangka Raya. 